\title{
O NOVO CPC E O DIREITO COMO INTEGRIDADE
}

\author{
Alessandra Damian Cavalcanti ${ }^{369}$
}

Recebido em: 25/08/2016

Aprovado em: 12/09/2016

\begin{abstract}
RESUMO
O presente artigo trata sobre as alterações promovidas no novo código de processo civil para que os Tribunais uniformizem sua jurisprudência e a mantenham estável, íntegra e coerente à luz da teoria de Ronald Dworkin, do direito como integridade e da metáfora do romance em cadeia na produção das decisões judiciais. Trata ainda da falta de uniformidade nas decisões judiciais no Brasil, não há previsibilidade, o que gera insegurança jurídica. Analisar-se-á a proposta de Dworkin, que trata do Direito como integridade em sua dupla dimensão. A integridade da legislação como mais um obstáculo a ser superado para alcançar a integridade no ordenamento. As decisões proferidas em um sistema jurídico em que os tribunais devem uniformizar sua jurisprudência e mantê-la estável, íntegra e coerente, conforme prevê o art. 926 do Novo Código de Processo Civil são decisões mais aptas ao controle, à crítica. Se o dispositivo for observado pelos julgadores haverá uma melhora qualitativa do sistema jurídico.
\end{abstract}

Palavras-chave: Novo código de processo civil. Coerência. Integridade.

\section{INTRODUÇÃO}

O novo Código de Processo Civil -- Lei no 13.105/2015 -- entrou em vigor em março de 2016, dentre as mudanças contidas na novel legislação, destaca-se uma mudança de paradigmas, que se de fato for observada poderá ser extremamente positiva para o sistema jurídico brasileiro, sobretudo para os jurisdicionados. Trata-se da previsão contida no artigo 926 da Lei $\mathrm{n}^{\mathrm{0}} 13.105 / 2015$.

\footnotetext{
${ }^{369}$ Advogada, pós-graduada em Direito Constitucional pelo Instituto Brasiliense de Direito Público IDP, mestranda em Direito Constitucional e Sociedade no Instituto Brasiliense de Direito Público IDP. Endereço eletrônico: alessandradamian@ hotmail.com.
} 
O dispositivo do novo Código deverá ser aplicado pelos magistrados - e demais operadores do direito - e prevê que "os tribunais devem uniformizar sua jurisprudência e mantêla estável, íntegra e coerente". 370

O presente artigo pretende analisar o referido dispositivo à luz da teoria de Ronald Dworkin, a partir da sua concepção acerca da interpretação do Direito, da ideia do Direito como integridade e a do romance em cadeia (DWORKIN, 2007).

Nesse espeque, a coerência e a integridade na jurisprudência atuam na concretização do princípio da igualdade, para que casos iguais tenham o mesmo desfecho e para que haja um certo grau de previsibilidade nas decisões.

Dessa forma, analisar-se-á em que medida a aplicação da teoria de Dworkin sobre interpretação do Direito contribui para o sistema jurídico brasileiro, para que a jurisprudência seja estável, íntegra e coerente, como pretende o novo Código de Processo Civil e quais são os obstáculos enfrentados no Brasil para alcançar o Direito como integridade.

\section{A FALTA DE UNIFORMIDADE E DE SEGURANÇA JURÍDICA NAS DECISÕES JUDICIAIS}

O direito, como meio de pacificação social, deve gerar a estabilidade das relações, proporcionando segurança jurídica aos jurisdicionados, isso significa que as decisões devem conter certo grau de previsibilidade.

MacCormick (2008, p. 21-22 e p.352) destaca que:

Onde há, em uma dada comunidade, um corpo de normas jurídicas estabelecido e reconhecido, destinado a governar os arranjos entre todas as pessoas nessa dada comunidade, a estrita observância dessas normas jurídicas por aqueles que detêm poder de governo é de valor inestimável. Onde o Direito é estritamente observado, o Estado de Direito se estabelece; [...] Entre os valores que ele assegura, nenhum é mais importante do que a certeza jurídica, exceto talvez pelos princípios que a acompanham, a saber, a segurança de expectativas jurídicas e a garantia ao cidadão contra interferências arbitrárias por parte do governo e de seus agentes. Isso porque uma sociedade que alcança esses ideais de certeza e segurança jurídicas permite a seus cidadãos viverem vidas autônomas em circunstâncias de mútua confiança. [...] as pessoas podem ter, antecipadamente, razoável certeza a respeito das regras e padrões segundo os quais sua conduta será julgada e sobre os requisitos que elas devem satisfazer para dar validade jurídica às suas transações.

$[\ldots]$

O Direito não é uma abstração onipresente no céu, como Oliver Wendell Holmes Jr. colocou, mas uma questão de decisões e opiniões de ontem e de hoje, e ainda mais de amanhã. Conhecer o Direito é saber como prever o que as autoridades decisórias vão

370 BRASIL. Lei $\mathrm{n}^{\mathrm{o}} 13.105$ de 16 de março de 2015. Disponível em: http://www.planalto.gov.br/ccivil_03/_Ato2015-2018/2015/Lei/L13105.htm. Compulsado em 07/01/2016 
decidir, e não conhecer um conjunto de proposições que poderiam estar escritas num manual. [...] A decisão judicial requer sempre um balanceamento entre as demandas do justo e aquelas do útil. Nisso agentes decisórios individuais podem facilmente errar. Portanto, pode tomar tempo para que emerja uma linha de decisões que mereça total respeito como Direito estabelecido. O Direito legislado tem menor probabilidade de ser preciso, uma vez que o legislador tem que dar a solução correta para todos os problemas de um único golpe.

Também no sistema de Civil Law a jurisprudência representa uma fonte do Direito, cada vez mais importante. É notório, no entanto, que ocorre no Brasil uma flagrante falta de uniformidade nas decisões judiciais, o que gera uma considerável insegurança nos operadores do direito e a dificuldade de se identificar com clareza qual é o entendimento de um tribunal sobre um tema específico, frente à ampla gama de decisões em diferentes sentidos tratando sobre a mesma matéria.

As mudanças constantes nas decisões sobre determinados temas criam uma imensa confusão no sistema jurídico brasileiro, o que contribui para a multiplicação de recursos, para o aumento da quantidade de processos nos tribunais, uma vez que não há entendimento consolidado sobre determinadas matérias as partes são estimuladas a tentar obter o provimento jurisdicional que desejam. $\mathrm{O}$ aumento da quantidade de processos gera, consequentemente, $\mathrm{o}$ aumento da duração da tramitação dos processos, uma vez que a estrutura física e de recursos humanos dos Tribunais permanece a mesma.

O jurisdicionado quando busca o Judiciário para a solução de uma controvérsia, na maioria das vezes, não tem como prever minimamente como se dará a o desfecho da lide, não sabe quando, tampouco se seu processo terá o mesmo desfecho de outra lide idêntica já decidida.

Essa situação de insegurança e incerteza é prejudicial não só para os operadores do Direito, mas para toda a sociedade.

Para ilustrar essa realidade, convém transcrever excertos de um voto que ficou muito conhecido, proferido pelo ministro do Superior Tribunal de Justiça, Humberto Gomes de Barros, em que o ministro destaca:

[...]. Nós somos os condutores, e eu - Ministro de um Tribunal cujas decisões os próprios Ministros não respeitam - sinto-me, triste. Como contribuinte, que também sou, mergulho em insegurança, como um passageiro daquele voo trágico em que o piloto que se perdeu no meio da noite em cima da Selva Amazônica: ele virava para a esquerda, dobrava para a direita e os passageiros sem nada saber, até que eles de repente descobriram que estavam perdidos: o avião com o Superior Tribunal de Justiça está extremamente perdido. Agora estamos a rever uma Súmula que fixamos há menos de um trimestre. Agora dizemos que está errada, porque alguém nos deu uma lição dizendo que essa Súmula não devia ter sido feita assim.

Nas praias de Turismo, pelo mundo afora, existe um brinquedo em que uma enorme boia, cheia de pessoas é arrastada por uma lancha. A função do piloto dessa lancha é 
fazer derrubar as pessoas montadas no dorso da boia. Para tanto, a lancha desloca-se em linha reta e, de repente, descreve curvas de quase noventa graus. O jogo só termina, quando todos os passageiros da boia estão dentro do mar. Pois bem, o STJ parece ter assumido o papel do piloto dessa lancha. Nosso papel tem sido derrubar os jurisdicionados. $^{371}$

Esse quadro de instabilidade das decisões é verificado tanto nas Cortes ordinárias quanto nos Tribunais Superiores, conforme ilustrado pelo voto do Ministro do Superior Tribunal de Justiça acima citado.

Este é um cenário prejudicial para os operadores do direito, para juristas, magistrados, para os cidadãos, enfim, para toda a sociedade que depende do Poder Judiciário para solucionar seus conflitos - agrava-se a crise do Judiciário e distancia-se cada vez mais do ideal de justiça dworkiano, que prevê a igualdade de consideração. (DWORKIN, 2011)

Para Luciano Fuck (2016):

O principal patrimônio de uma Corte é sua legitimidade, sua credibilidade. Esses valores são comprometidos quando a volatilidade das decisões é tão grande que se torna impossível ao jurisdicionado antecipar se determinado entendimento será reiterado ou simplesmente ignorado no futuro próximo. Se, nas Cortes ordinárias, a importância da estabilidade de entendimentos já é evidente, nos Tribunais Superiores, ela é indispensável para cumprimento de sua missão institucional, principalmente para pacificar dissensos pretorianos e fixar a interpretação de normas.

Do mesmo modo, Erik Navarro Wolkart (2013, p. 19) indica que a morosidade do poder judiciário, a imprevisibilidade das decisões, a instabilidade da jurisprudência e a transformação dos tribunais superiores em meras instâncias revisionais, indicam as mazelas atuais da atividade jurisdicional.

Na verdade, certas mazelas e a instabilidade da jurisprudência são problemas atuais, mas não são problemas de origem recente, existe um contexto histórico que é preciso considerar e que explica - não justifica - como é que se chegou até aqui.

Keith Rosenn aponta esses vícios e tece um diagnóstico interessante do sistema jurídico brasileiro e as suas principais características, decorrentes do processo histórico, com origens que remontam ao período da colonização pelos portugueses que culminaram no "jeito". (ROSENN, 1998)

Rosenn (1998, p.101) aponta que "a falta de uma estrutura jurídica previsivel dificulta o planejamento de negócios. Transações veladas pela legalidade dúbia do jeito podem funcionar às mil maravilhas hoje e desmoronar amanhã’.

371 BRASIL. AgRG no REsp 382736/SC de 25/02/2004. Disponível em < https://ww2.stj.jus.br/processo/pesquisa/?tipoPesquisa=tipoPesquisaNumeroRegistro\&termo=200101557448\& to talRegistrosPorPagina=40\&aplicacao=processos.ea>. Compulsado em 07/01/2016. 
Rosenn reconhece que nas últimas décadas têm-se adotado medidas que buscam conferir mais segurança jurídica e previsibilidade nas decisões judiciais, mas o cenário atual ainda está distante de alcançar o grau de previsibilidade e segurança almejados.

Para Lenio Streck (1999, p. 35):

A crise do modelo (modelo de produção do Direito) se instala justamente porque a dogmática jurídica, em plena sociedade transmoderna e repleta de conflitos transindividuais, continua trabalhando com a perspectiva de um Direito cunhado para enfrentar conflitos interindividuais, bem nítidos em nossos Códigos (civil, comercial, penal, processual penal e processual civil, etc.). Esta é a crise de modelo (ou modo de produção) de Direito, dominante nas práticas jurídicas de nossos tribunais, fóruns e na doutrina. No âmbito da magistratura - e creio que o raciocínio pode ser estendido às demais instâncias de administração da justiça - aponta dois fatores que contribuem para o agravamento dessa problemática: o excessivo individualismo e o formalismo na visão de mundo: esse individualismo se traduz pela convicção de que a parte precede o todo, ou seja, de que os direitos do indivíduo estão acima dos direitos da comunidade.

Cita-se o diagnóstico de Luiz Guilherme Marinoni (2011, p. 63-64):

Trata-se de algo realmente curioso. Embora a praxe tenha constatado que de nada adianta a lei quando o cidadão não sabe o que esperar dos juízes, a única preocupação da doutrina tem sido a de demonstrar que, apesar de ter se tornado evidente que o juiz presta a tutela jurisdicional indo muito além da mera aplicação da lei, isso não significa negação do princípio da separação dos poderes. Ou melhor, a doutrina não tomou consciência de que, diante da variedade das decisões e interpretações da lei, seria necessária uma elaboração dogmática capaz de garantir a segurança, a previsibilidade e a igualdade. Há que se dizer, sem qualquer pudor, que a doutrina do civil law cometeu o pecado grave ao encobrir a necessidade de um instrumento capaz de garantir a igualdade diante das decisões, fingindo crer que a lei seria bastante e preferindo preservar o dogma em vez de denunciar a realidade e a funesta consequência dela derivada.

Sem dúvida, o sistema de precedentes estabelecido no common law é uma ferramenta útil para buscar essa uniformização das decisões judiciais e corrobora com a ideia de integridade e coerência do sistema jurídico.

Para Fredie Didier Junior o stare decisis constitui apenas um elemento do common law, e, por isso, pode conviver com o sistema de civil law. (DIDIER JUNIOR, 2006, p. 183)

É indiscutível que elementos de sistematização, estabilidade, coerência e integridade das decisões judiciais são essenciais para promover a segurança jurídica e a previsibilidade das decisões judiciais.

Em um cenário de crise e de incertezas, o sistema jurídico não pode equivaler a uma loteria, onde fatores como a sorte ou o azar se sobrepujam aos argumentos.

Enquanto a instabilidade se propaga o número de processos cresce em progressão geométrica potencializando a inconstância da jurisprudência e a insegurança jurídica, perfazendo o retrato de uma preocupante realidade. 
Algumas mudanças foram promovidas ainda no Código de Processo Civil de 1973, por meio dos artigos 285-A, 518, 543-B, 543-C, 557 do referido diploma, medidas que poupam tempo e privilegiam a jurisprudência das Cortes Superiores.

Ocorre que, mesmo com a criação dos mecanismos acima referidos, diante da complexidade e profundidade dos problemas em nosso sistema jurídico, permanece o cenário de falta de segurança jurídica e de carência de sistematização e uniformidade nos precedentes.

Tereza Arruda Alvim Wambier (2009, p. 121-174) aponta para as divergências nos tribunais superiores:

Quando um dos tribunais superiores profere uma decisão, espera-se que, justamente em virtude da missão que lhes foi atribuída pela Constituição Federal, daquela decisão se extraia verdadeiro modelo de atuação, para os próprios tribunais e para todos os demais órgãos do Judiciário, de modo que, mesmo que ainda não sumulado um determinado entendimento, sirva, aquela decisão judicial, como parâmetro para os julgamentos futuros.

A função constitucional do STF e do STJ fica comprometida pela intensidade de divergência jurisprudencial interna corporis provocada por estes mesmos tribunais. Isso porque, em vez de funcionarem como tribunais que deem ensejo à uniformização do entendimento relativo à norma constitucional ou federal, ao manterem profunda $\mathrm{e}$ insistente discrepância acerca de determinadas questões jurídicas, referidos tribunais proporcionam justamente o resultado oposto, qual seja a insegurança e intranquilidade acerca de como deve ser interpretada uma norma constitucional ou federal.

Nesse sentido Luhmann (1983, p. 52-53) assevera que o Direito, como expectativa das expectativas cria:

[...] uma segurança a qual se segue, apenas secundariamente, a segurança sobre o comportamento próprio e a previsibilidade do comportamento alheio. É muito importante, para a compreensão do direito, ter uma visão clara dessa diferença. Isso porque a segurança na expectativa sobre expectativas, seja ela alcançada por meio de estratégias puramente psíquicas ou por normas sociais, é uma base imprescindível de todas as interações, e muito mais importante que a segurança na satisfação das expectativas.

O Direito tem como função estabilizar expectativas de condutas e regular conflitos por meio de procedimentos que assegurem esse objetivo, não é possível estabilizar as expectativas sem previsibilidade e sem segurança jurídica.

Para Lenio Streck (2009, p. 284-319):

Se é certo que o papel da jurisprudência é cada vez mais importante, também é certo que é preciso um estudo mais rigoroso da teoria do precedente e um aprimoramento na utilização das técnicas desenvolvidas a partir desse conjunto teórico. E uma das técnicas mais importantes é, justamente, a técnica de 'redação do preceito normativo jurisprudencial', a ratio decidendi, a 'norma jurídica geral' construída a partir de casos concretos. 
É neste contexto que foi inserido no novo Código de Processo Civil o artigo 926: Os tribunais devem uniformizar sua jurisprudência e mantê-la estável, integra e coerente.

É preciso destacar que foi a contundente crítica acadêmica de Lenio Luiz Streck que permitiu uma abertura no diálogo durante a tramitação no Congresso Nacional e a introdução da coerência e integridade na discussão sobre a estabilidade da jurisprudência, que levou ao aperfeiçoamento do Projeto do Novo Código, por meio de sugestão de emenda apresentada por Lenio Streck acatada pelo relator do projeto de lei.

A par disso, destaca Lenio Streck (2014):

\begin{abstract}
Assim, haverá coerência se os mesmos preceitos e princípios que foram aplicados nas decisões o forem para os casos idênticos; mais do que isto, estará assegurada a integridade do direito a partir da força normativa da Constituição. A coerência assegura a igualdade, isto é, que os diversos casos terão a igual consideração por parte do Poder Judiciário. Isso somente pode ser alcançado através de um holismo interpretativo, constituído a partir de uma circularidade hermenêutica. Já a integridade é duplamente composta, conforme Dworkin: um princípio legislativo, que pede aos legisladores que tentem tornar o conjunto de leis moralmente coerente, e um princípio jurisdicional, que demanda que a lei, tanto quanto possível, seja vista como coerente nesse sentido. A integridade exige que os juízes construam seus argumentos de forma integrada ao conjunto do direito, constituindo uma garantia contra arbitrariedades interpretativas; coloca efetivos freios, através dessas comunidades de princípios, às atitudes solipsistas-voluntaristas. A integridade é antitética ao voluntarismo, do ativismo e da discricionariedade.
\end{abstract}

Assim, a estabilidade e a coerência das decisões judiciais não diminuem o protagonismo judicial, mas certamente diminuem o grau de discricionariedade nas decisões judiciais.

Lenio Streck (2015) ainda destaca que nenhuma decisão ocorre no vácuo, mas em um contexto histórico-institucional, assevera que na fundamentação é essencial que esse contexto histórico-institucional seja explicitamente apontado, alerta que a tese dos precedentes, que se almeja privilegiar no novo código, se for mal aplicada, deparar-se-á com uma:

[..] falácia semântica ou na crença na plenipotenciariedade dos conceitos, como se fosse possível a uma lei, a uma súmula ou a uma ementa jurisprudencial prever todas as hipóteses de aplicação de forma antecipada. Nesse sentido, a tese dos precedentes só funcionará se adotar uma postura hermenênutica, aquilo que se denomina de applicatio a partir de Gadamer e que foi retrabalhado por mim na Crítica Hermenêutica do Direito.

O anteprojeto do novo Código de Processo Civil ${ }^{372}$ elaborado por uma Comissão de Juristas, presidida pelo Ministro Luiz Fux, destacou que seriam necessárias reformas mais profundas no processo judiciário, fundamentais para uma Justiça mais rápida e mais efetiva.

372 BRASIL. Congresso Nacional. Senado Federal. Comissão de Juristas Responsável pela Elaboração de Anteprojeto de Código de Processo Civil. Código de Processo Civil: anteprojeto / Comissão de Juristas Responsável pela Elaboração de Anteprojeto de Código de Processo Civil. - Brasília: Senado Federal, Presidência, 2010 . 
Dessa forma, um dos objetivos do novo Código de Processo Civil foi expressamente a estabilização e uniformização da jurisprudência ${ }^{373}$, a Comissão de Juristas pontuou que a segurança jurídica fica comprometida com a "brusca e integral alteração do entendimento dos tribunais sobre questões de direito."

Para Luiz Fux (2010), presidente da Comissão de Juristas formada para a elaboração do anteprojeto do NCPC, a intenção é de fortalecer significativamente os precedentes judiciais:

\begin{abstract}
A força da jurisprudência adquiriu notável relevo em todos os graus de jurisdição, viabilizando a criação de filtros em relação às demandas ab origine, autorizando o juiz a julgar a causa de plano consoante a jurisprudência sumulada e oriunda das teses resultantes dos recursos repetitivos, sem prejuízo de tornar obrigatório para os tribunais das unidades estaduais e federais a adoção das teses firmadas nos recursos representativos das controvérsias, previstos no artigo 543-C do CPC, evitando a desnecessária duplicação de julgamentos, além de fortalecer uma das funções dos Tribunais Superiores, que é a de uniformizar a jurisprudência do país.
\end{abstract}

Dworkin (2007, p. 271) defende - mesmo reconhecendo que existem divergências quanto ao sentido das normas jurídicas - uma visão de conjunto, a integridade no Direito.

Assim, buscar-se-á com a nova legislação uma concepção dowrkiana do Direito.

\title{
3 A INTERPRETAÇÃO DO DIREITO PARA RONALD DWORKIN
}

A teoria da integridade pressupõe o aspecto legislativo e o aspecto jurisdicional, o parlamento como responsável pela produção legislativa, que deve tornar o conjunto de leis do Estado moralmente coerente, e os magistrados, por meio da coerência moral na atuação judicante.

Para Dworkin o Direito como integridade é contrário à ideia de que as manifestações do Direito sejam relatos factuais do convencionalismo, voltados para o passado ou programas instrumentais do pragmatismo jurídico, voltados para o futuro, a interpretação combina elementos que se voltam tanto para o passado quanto para o futuro, como uma política em processo de desenvolvimento. (DWORKIN, 2007, p. 271)

373 Prestigiou-se, seguindo-se direção já abertamente seguida pelo ordenamento jurídico brasileiro, expressado na criação da Súmula Vinculante do Supremo Tribunal Federal (STF) e do regime de julgamento conjunto de recursos especiais e extraordinários repetitivos (que foi mantido e aperfeiçoado) tendência a criar estímulos para que a jurisprudência se uniformize, à luz do que venham a decidir tribunais superiores e até de segundo grau, e se estabilize. Essa é a função e a razão de ser dos tribunais superiores: proferir decisões que moldem o ordenamento jurídico, objetivamente considerado. A função paradigmática que devem desempenhar é inerente ao sistema. Código de Processo Civil: anteprojeto / Comissão de Juristas Responsável pela Elaboração de Anteprojeto de Código de Processo Civil. - Brasília: Senado Federal, Presidência, 2010. 
Dworkin trata a decisão judicial como uma peça na qual o juiz age interpretando todos os princípios morais e legais de uma comunidade, trazendo-os para o caso concreto e fazendo a devida interpretação construtiva, dando a melhor interpretação possível dentro do caso concreto, sob o prisma político da situação, amparada também em uma detida análise dos precedentes.

Assim, para Dworkin, o princípio de integridade pressupõe que os juízes identifiquem direitos e deveres como se tivessem sido criados por um único autor, que seria a comunidade personificada, numa concepção coerente de justiça e equidade, as proposições jurídicas são verdadeiras se derivam dos princípios de justiça, equidade, devido processo legal que oferecem a melhor interpretação construtiva da prática jurídica da comunidade.

Como Dworkin distingue o Direito como integridade do pragmatismo ou do convencionalismo, ele é tanto o produto da interpretação abrangente da prática jurídica quanto sua fonte de inspiração. (DWORKIN, 2007, p. 274)

Dessa forma, a atividade judicante deve ser coerente, fiel a princípios como equidade, justiça, legalidade, integridade e os juízes são instruídos a identificar direito e deveres legais, partindo do pressuposto que foram criados "por um único autor".

A interpretação criativa, portanto, busca sua estrutura formal na ideia de intenção, mas não o faz com base nos propósitos de uma pessoa ou grupo histórico específico, serve para conferir um propósito ao texto, dados ou tradições objetos da interpretação, o juiz pode inclusive introduzir acréscimos na tradição que interpreta.

Nesse sentido, Dworkin traça um modelo interpretativo, um gênero literário artificial comparando a literatura ao direito - denominado "romance em cadeia" no qual diferentes escritores têm a tarefa de elaborar um capítulo de um livro, mas que deve interpretar os capítulos anteriores escritos por outros escritores e considerando ainda aquilo que os seus sucessores poderão criar. (DWORKIN, 2007, p. 276)

Esse procedimento envolve não apenas uma avaliação geral da parte de quem está a escrever aquele determinado capítulo, mas uma visão de desenvolvimento, de formação, de continuidade e não uma série de recomeços, surge então a ideia de adequação e de interpretação, como dimensões de avaliação do texto, para alcançar esse resultado integrado.

MacCormick enfatiza que: "Em uma discussão jurídica, ninguém começa a partir de uma folha em branco e tenta alcançar uma conclusão razoável a priori”. (MACCORMICK, 2008, p. 31)

O juiz então atua como autor e também como crítico, ele terá que considerar o que os outros juízes decidiram em casos análogos, extraindo uma interpretação que ao mesmo tempo 
se adapte aos fatos anteriores e os justifique, numa complexa interação entre a adequação e a justificação:

\begin{abstract}
Qualquer conjunto de leis e decisões pode ser explicado histórica, psicológica ou sociologicamente, mas a consistência exige uma justificação, e não uma explicação, e a justificação deve ser plausível, e não postiça. Se a justificação que Hércules concebe estabelece distinções que são arbitrárias, e se vale de princípios que não são convincentes, então ela não pode, de modo algum, contar como uma justificação. (DWORKIN, 2002, p. 186)
\end{abstract}

A intepretação representa para cada intérprete "um delicado equilíbrio entre convicções políticas de diversos tipos. " (DWORKIN, 2007, P. 287)

Para realizar essa tarefa complexa, Dworkin (2007, p. 287-294) apresenta o juiz Hércules, criterioso, metódico, um juiz filósofo, que seleciona diversas hipóteses para corresponderem à melhor interpretação dos casos precedentes, aplicando princípios subjacentes a cada interpretação e verificando se cada questão está amparada em um princípio de justiça, rechaçando as hipóteses que não se amoldam a essa premissa, de tal modo que a situação de cada pessoa seja justa e equitativa segundo as mesmas normas:

Nenhum juiz real poderia impor nada que, de uma só vez, se aproxime de uma
interpretação plena de todo o direito que rege sua comunidade. É por isso que
imaginamos um juiz hercúleo, dotado de talentos sobre-humanos e com um tempo
infinito a seu dispor. Um juiz verdadeiro, porém, só pode imitar Hércules até certo
ponto.

O juiz Hércules de Dworkin adota o Direito como integridade, vez que está convencido de que oferece uma melhor adequação e uma melhor justificativa da prática jurídica como um todo, numa abordagem marcada, sobretudo, pelas perguntas, mais do que pelas respostas, as perguntas são vitais para que se possa vislumbrar todos os pontos de vista distintos, para rejeitálos ou considerá-los, numa justificação que seja ao mesmo tempo consistente com os valores da comunidade de princípios e seja uma ponte interligando passado, presente e futuro.

Dessa forma, para Dworkin o direito como integridade pede que os juízes admitam, na medida do possível, que o direito é estruturado por um conjunto coerente de princípios sobre a justiça, a equidade e o devido processo legal adjetivo, respeitando a ambição de uma comunidade de princípios.

Dworkin ressalta, contudo, que o Direito como integridade pressupõe que os juízes se encontram em situação muito diversa dos legisladores, os juízes devem basear suas decisões em princípios e não em política e os juízes não devem, em momento algum, fazer escolha entre 
suas próprias convicções políticas e aquelas que ele considera como as convicções políticas do conjunto da comunidade.

A moralidade comunitária - como moralidade política que as leis e as instituições da comunidade pressupõem - constitui fator decisivo para os problemas jurídicos. (DWORKIN, 2002, p. 197-198)

A interpretação do Direito pelo juiz Hércules em um caso difícil será sempre assentada na moral, mesmo que seja a moral política, residindo nos princípios a fonte da moralidade do Direito como integridade.

O juiz Hércules rejeita o pragmatismo e procura fazer uma interpretação construtiva da compartimentalização do direito, na qual está obrigatoriamente vinculado a um compromisso de oferecer uma justificativa de acordo com a história legislativa, moral e política do contexto em que o caso se assenta, assim como, de demonstrar que sua decisão foi baseada em princípios e não em compromissos ou estratégias políticas.

Dworkin (2007, p. 299) destaca que:

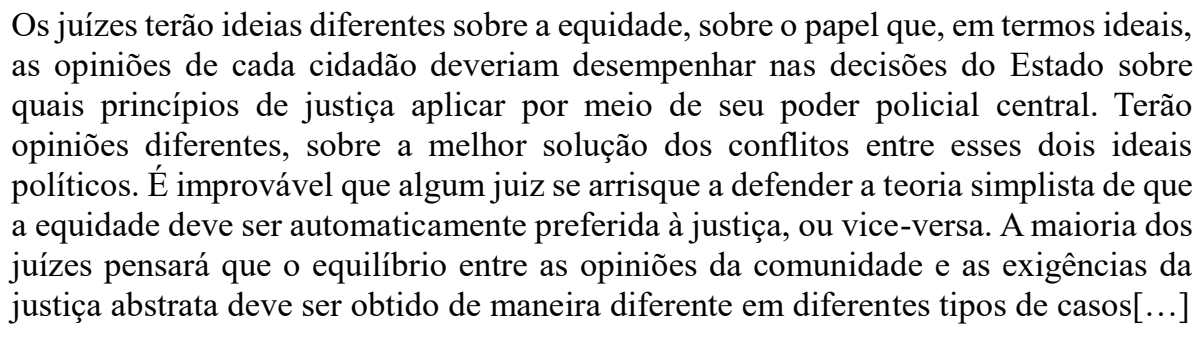

A integridade não se confunde com a justiça e com a equidade, embora estejam interligadas, como elucida Dworkin:

\begin{abstract}
Aceitamos a integridade como um ideal político porque queremos tratar nossa comunidade política como uma comunidade de princípios, e os cidadãos de uma comunidade de princípios não têm por único objetivo princípios comuns, como se a uniformidade fosse tudo que desejassem, mas os melhores princípios comuns que a política seja capaz de encontrar. A integridade é diferente da justiça e da equidade, mas está ligada a elas da seguinte maneira: a integridade só faz sentido entre pessoas que querem também justiça e equidade. (DWORKIN, 2007, p. 314)
\end{abstract}

O novo Código de Processo Civil traduz uma ideia de que o legislador, responsável pela edição da norma - Lei n. 13.105/2015 - com base nos princípios comuns de nossa sociedade, está buscando promover a integridade no sistema jurídico brasileiro e que isso deverá refletir nas interpretações gerais de nossa prática judicial. 


\section{A INTEGRIDADE}

Para Dworkin (2007, p. 202) a integridade constitui a terceira virtude política, juntamente com a justiça e o devido processo legal, a integridade impõe que o governo atue de modo coerente e fundamentado em princípios, para proporcionar a todos os cidadãos padrões fundamentais de justiça e equidade.

Dessa forma, a integridade é ideia que está ligada à uma comunidade de princípios:

Mostrarei que uma sociedade política que aceita a integridade como virtude política se transforma, desse modo, em uma forma especial de comunidade, especial num sentido de que promove sua autoridade moral para assumir e mobilizar monopólio de força coercitiva. Este não é o único argumento em favor da integridade, ou a única consequência de reconhecê-la que poderia ser valorizada pelos cidadãos. A integridade protege contra a parcialidade, a fraude ou outras formas de corrupção oficial, por exemplo. (DWORKIN, 2007, p. 228)

Assim, integridade contribui para a eficiência do direito, pois conduz à ficção jurídica de que os direitos e deveres legais possuem um único autor, que seria a comunidade personificada, que seria a guardiã da justiça e da equidade.

A integridade constitui um limite imanente ao princípio do livre convencimento do juiz, tão alargado em nosso sistema jurídico brasileiro, o que não significa, como criticam alguns, que o juiz deva ser considerado apenas como a bouche de la loi de Montesquieu em o Espírito das Leis (WOLKART, 2013, p. 247).

Tampouco um mero reprodutor aleatório de precedentes automatizado, como enfatiza Dworkin (2005, p. 25):

Os juízes devem impor apenas convicções políticas que acreditam, de boa-fé, poder figurar numa interpretação geral da cultura jurídica e política da comunidade. Naturalmente, os juristas podem, razoavelmente, discordar sobre quando essa condição é satisfeita, e convicções muito diferentes, até mesmo contraditórias podem passar pelo teste. Mas algumas não. Um juiz que aceita esse limite e cujas convicções são marxistas ou anarquistas, ou tiradas de alguma convicção religiosa excêntrica, não pode impor essas convicções à comunidade com o título de Direito, por mais nobres ou iluminadas que acredite que sejam, pois elas não se podem prestar à interpretação geral coerente de que ele necessita.

Dessa forma, pode o magistrado decidir de acordo com a sua própria moralidade política, contanto que esta seja compatível com um conjunto de princípios, o convencimento não pode ser tão livre assim e não basta ser motivado, os motivos devem estar amparados nos princípios aceitos pela comunidade dos princípios e coerentes com o nosso sistema.

Dworkin pretende que ao se aplicar o método interpretativo por ele proposto, dar-se-á à norma jurídica um sentido mais consistente com a prática jurídica, numa perspectiva mais 
ampla, de modo que os juízes não estariam tão livres para decidir de acordo com o seu livre convencimento, há um grau de racionalidade maior que envolve essa integração sistêmica que afasta a ampla discricionariedade.

Assim, a interpretação construtiva impõe um propósito a um objeto ou prática a fim de torná-lo o melhor possível. Isto não significa que possa fazer o que bem entenda, pois, a história de uma prática, ou a forma de um objeto, traça limites às interpretações disponíveis. (DWORKIN, 2007, p. 65)

Lenio Streck (2015) destaca que o livre convencimento do juiz está em um "exílio epistêmico" e o novo Código de Processo Civil rompeu com o velho modelo. Nota-se que foi preciso alterar a norma para tentar eliminar um grau de subjetivismo que não deveria nem existir, não pode haver espaço para arbitrariedades quando se busca o Direito como integridade e a estabilidade das relações jurídicas.

Cumpre ressaltar que isso não significa que não poderá haver uma quebra da cadeia decisória, mas que esta quebra dar-se-á em conformidade com uma consistência principiológica ampla, dentro do romance em cadeia, interligando passado, presente e futuro.

É preciso fundamentar - justificação - porque deixou-se de seguir enunciado de súmula, jurisprudência ou precedente invocado pela parte, demonstrando claramente o distinguishing quando for o caso. ${ }^{374}$

As previsões contidas no Art. 489 e Art. $927^{375}$ do novo Código de Processo Civil, também revelam a busca da coerência e da integridade na jurisprudência.

Lenio Streck (2013) destaca que a estabilidade da jurisprudência é diferente da integridade e da coerência do Direito, a integridade e a coerência são dotadas de consciência histórica e consideram a facticidade do caso, guardando um substrato ético-político, destacando que coerência significa em casos semelhantes deve-se proporcionar a garantia da isonômica

374 Novo CPC:

Art. 489. São elementos essenciais da sentença:

[...]

$\S 1$ ํNão se considera fundamentada qualquer decisão judicial, seja ela interlocutória, sentença ou acórdão, que: $[\ldots]$

VI -deixar de seguir enunciado de súmula, jurisprudência ou precedente invocado pela parte, sem demonstrar a existência de distinção no caso em julgamento ou a superação do entendimento.

375 Art. 927. Os juízes e os tribunais observarão:

I - as decisões do Supremo Tribunal Federal em controle concentrado de constitucionalidade;

II - os enunciados de súmula vinculante;

III - os acórdãos em incidente de assunção de competência ou de resolução de demandas repetitivas e em julgamento de recursos extraordinário e especial repetitivos;

IV - os enunciados das súmulas do Supremo Tribunal Federal em matéria constitucional e do Superior Tribunal de Justiça em matéria infraconstitucional;

V - a orientação do plenário ou do órgão especial aos quais estiverem vinculados. 
aplicação principiológica, pelo que estará assegurada a integridade do direito a partir da força normativa da Constituição, pois a integridade pressupõe que os juízes construam seus argumentos de forma integrada ao conjunto do direito, rechaçando a tentação da arbitrariedade.

Assim, o novo Código de Processo Civil pressupõe um novo paradigma, distancia-se do velho modelo e privilegia a integridade do direito em detrimento do livre convencimento do juiz, buscando manter as decisões judiciais não só estáveis, mas íntegras e coerentes.

\subsection{A integridade não é imobilismo jurídico}

A regra da stare decisis, que significa, literalmente, permitir que a decisão se mantenha e é o mesmo que a doutrina de precedente. Peter Messitte (2001,p. 95) destaca que se espera que os tribunais sigam sentenças emitidas em processos anteriores e que isso de fato acontece, porque o importante é que valores e verdades objetivas razoáveis obriguem o Judiciário a se comportar desta forma e que o ativismo judicial, ou seja, o ato de criar leis, é oficialmente desencorajado.

O pensamento dos juristas norte-americanos favorece o desenvolvimento lógico de premissas aceitas, aliado à uma crença profunda na consistência, integridade e segurança, elementos que deram causa o surgimento da doutrina do precedente em primeiro lugar e que "o precedente é adotado se cada faceta da porção factual do caso subsequente é considerada parecida com aquelas do caso anterior. " (MESSITTE, 2001, p. 96)

Bruce Ackerman utiliza uma metáfora para a atividade judicante: "judges as passengers in the caboose of a train, looking backward at he view behind then" mas o papel dos juízes é tentar dar sentido à paisagem que os formuladores de políticas, os legisladores esculpiram e o caminho que escolheram. (apud BENJAMIN, 1999, p. 371/372)

Entretanto, a estabilidade das decisões judiciais sob a ótica do Direito como integridade não implica no engessamento das decisões judiciais.

O Direito evolui com a sociedade e o romance em cadeia permite que ocorra essa evolução de forma coerente com o ordenamento e com os valores da comunidade de princípios.

No sistema de Common Law norte-americano existem ferramentas jurídicas que permitem a evolução do Direito sem comprometer a ideia de coerência e integridade.

O overruling é a superação, consiste em decisão que altera de forma total o entendimento exarado no precedente, inclusive a mudança de membros na composição da Corte pode implicar em alguns casos no overruling de determinadas matérias, mas a corte tem ciência 
que está promovendo essa mudança e na decisão judicial são expostas as razões da mudança de entendimento, dos motivos da superação do entendimento anteriormente predominante.

Para Eisenberg (1991, p. 104-105) o overruling tem lugar quando: não se satisfazem mais as exigências de congruência social e consistência sistêmica e os valores que legitimam o efeito vinculante, tais como proteção de justificável confiança, defesa contra a injusta surpresa, previsibilidade, isonomia, não prevalecem sobre os motivos que justificam sua invalidação.

O compromisso com a coerência e com a integridade é tamanho que a implementação do overruling, ainda que se mostre necessária, considera ainda as expectativas geradas pela regra anterior, daí que a alteração do precedente pode ocorrer com efeitos limitados, aplicandose aos processos pendentes de julgamentos (limited prospectivity) ou excluindo de forma absoluta a eficácia ex tunc (pure prospectivity).

Outra ferramenta é o overriding, que ocorre quando a corte reduz o âmbito de uma doutrina anteriormente estabelecida em favor de uma regra ou princípio legal que surgiu depois que a antiga doutrina foi estabelecida. (EISENBERG, 1991, p. 135)

Dessa forma o overriding representa uma revogação parcial de um precedente geral que acaba por ter sua aplicação restringida diante de uma norma especial que justifica a alteração da abrangência do precedente.

Sem falar na mutação constitucional ou living constitution (ACKERMAN, 2007) quando os resultados da concretização da norma modificam-se, embora o texto da norma fique idêntico, coordenando o dinamismo constitucional com a estabilidade (HESSE, 2008, P. 4551), nesse caso o exemplo clássico do overruling em Brown v. Board of Education ${ }^{376}$, que superou Plessy v. Ferguson ${ }^{377}$.

Assim, não é possível confundir a integridade com a estagnação das decisões judiciais e do Direito, não é disso que se cuida.

O Direito deve evoluir com a sociedade, assim como a legislação, mas é preciso um maior cuidado com a segurança jurídica, como subprincípio do Estado de Direito.

As mudanças não são frequentes e nem repentinas, são construídas dentro desse "romance em cadeia" de acordo com as mudanças sociais e evolução da comunidade de princípios.

4.2 Da integridade da legislação

376347 U.S. 483 (1954)

377163 U.S. 537, 552 (1896) 
A integridade para Dworkin pressupõe uma dupla dimensão para alcançar esse ideal político que deve ser perseguido por uma comunidade: que é a integridade na legislação, que exige do legislador que mantenha a produção das leis coerente quanto aos princípios adotados por aquela comunidade; e a integridade do julgamento, para que o Judiciário mantenha a coerência do sistema ao decidir as demandas concretas.

Assim, para que o Judiciário possa produzir decisões coerentes, depende de uma reconstrução racional e coerente com direito vigente, sendo a coerência a chave para obter a integridade pretendida por harmonizar e integrar passado, presente e futuro.

Para Dworkin o legislador também tem importante participação para a consecução do ideal político de uma comunidade de princípios, que é o Direito como integridade, a produção de normas devem preservar a coerência.

Para MacCormick (2008, p. 251-252):

Poderíamos dizer que um conjunto de regras é coerente se todas elas satisfazem ou são concretizações de um princípio mais geral. [...] a coerência de normas (consideradas como um conjunto de algum tipo), depende de que elas "façam sentido" em virtude de serem racionalmente relacionadas como um conjunto instrumental ou intrinsecamente voltado para a realização de alguns valores comuns.

No sistema jurídico brasileiro a coerência normativa é um desafio que poderia comprometer a aplicação da teoria do Direito como integridade?

Rosenn (1998, p. 84) destaca que descobrir a norma vigente no Brasil pode ser uma tarefa quase tão difícil e desconcertante quanto era no tempo colonial, em razão do imenso número de leis vigentes, mas também pela baixa qualidade de algumas leis e regulamentações:

\footnotetext{
Ninguém sabe, na realidade, quantas leis estão em vigor no Brasil. Em vez de revogar especificamente as leis obsoletas, o estilo brasileiro é de terminar a nova legislação com um artigo determinando que todas as disposições em contrário ficam revogadas. A explicação desses "modos operandi" legislativo é simples: ninguém sabe quais as leis que conflitam com aquela recém promulgada.
}

Gilmar Mendes (2014, p. 87) também aponta para o problema de incoerência normativa por parte do constituinte:

O postulado do legislador racional, que não usa palavras excessivas e que não é incoerente em seus comandos, encontra nas realidades constitucionais desmentidos práticos que desafiam a criatividade do intérprete. Por vezes, não há como resolver, segundo os critérios técnicos tradicionais de hierarquia, especialidade ou cronológicos, certas antinomias internas, verificadas na redação do Texto Constitucional. O problema, nesses casos, radica na circunstância de duas regras diversas, a propósito de um mesmo pressuposto de fato, comandarem soluções díspares. 
A incoerência normativa no nosso sistema jurídico pode ser um complicador para o êxito na aplicação da teoria da integridade do Direito de Dworkin, de modo que é preciso que a sociedade, como "comunidade de princípios", cobre também a coerência do Poder Legislativo.

Esse é um desafio que impõe uma dificuldade a mais para o Direito como integridade no Brasil e mostra que a questão não está apenas afeta ao Judiciário, a ação do juiz é a posteriori, para julgar de modo coerente, sem as chamadas atitudes solipsistas-voluntaristas (STRECK, 2014), depende da existência de um ordenamento coerente, em um sistema jurídico repleto de contradições a atividade do juiz pode tornar-se um repto árduo e improdutivo sob a ótica da coerência e integridade.

\section{CONSIDERAÇÕES FINAIS}

Embora o sistema jurídico brasileiro ainda tenha, ao menos teoricamente, como principal fonte a norma escrita, as evoluções sociais, políticas e morais levaram à necessidade de um maior protagonismo do Poder Judiciário.

Talvez em razão da complexidade e da rapidez com que as transformações sociais foram ocorrendo sem que a legislação pudesse acompanhar essa dinâmica constante.

Experimentamos desde a Constituição Federal de 1988 um fortalecimento das instituições acompanhado de uma abertura principiológica do direito constitucional brasileiro, o que para Dworkin consiste no fundamento ético da nova ordem constitucional.

Ocorre que essa maior abertura aos princípios provocou nas decisões judiciais um efeito curioso -- e prejudicial -- entendido por alguns como uma maior amplitude na liberdade de decidir, uma maior discricionariedade no conjunto das decisões e o chamado decisionismo, amplamente criticado, por comprometer a coerência e a previsibilidade das decisões judiciais.

A atividade judicial ao interpretar uma norma criada pelo Legislador, ao conferir sentido à norma, pode levar à criação de direitos, mas essa atividade precisa ter limites, essa questão foi considerada no Projeto do Novo Código de Processo Civil.

O método de interpretação do Direito de Dworkin oferece, sem dúvida, maior legitimidade à atividade jurisdicional, atendendo a ideais de justiça, uma vez que procura alinhar a história, os princípios, a moral, os costumes e as normas legais nas decisões judiciais, proporcionando aos jurisdicionados maior previsibilidade e segurança nas decisões. 
O romance em cadeia pressupõe que o Direito não é um produto pronto e acabado, independente dos juízos morais e interesses políticos, para Dworkin o julgador não é apenas um aplicador de normas, o romance em cadeia é uma ferramenta importante, que contribui para a construção do Direito, mas que é, ao mesmo tempo, um limite. Por esta cadeia de precedentes que precisa considerar o passado, presente e futuro, o juiz não pode decidir de acordo com o "seu" livre convencimento.

Será que sem a atuação do juiz Hércules é possível alcançar o Direito como integridade na forma como se pretende?

Os fundamentos da integridade do Direito contidos na teoria de Ronald Dworkin para a realidade do sistema jurídico brasileiro, podem funcionar como um norte, como a direção correta de um objetivo que está longe de ser alcançado, mas que, sem dúvida, desde já, uma maior coerência será de grande valia para o nosso sistema.

Ademais, a ideia de Direito como integridade, considerando o romance em cadeia, é algo em permanente desenvolvimento, não é estático e acabado no tempo, mas a sua coerência é importante para uma teoria da decisão judicial.

Assim, não se pode olvidar, que à luz da teoria de Dworkin a integridade também deve ser vista no plano legislativo, que impõe ao legislador um ordenamento jurídico moralmente coerente.

Nosso ordenamento jurídico poderia ser considerado como moralmente coerente?

O Judiciário tem sido alvo de muitas críticas no que tange a imprevisibilidade das decisões judiciais, mas é possível criticar somente o Judiciário quando a atividade legislativa não observa a coerência do sistema quando edita normas?

É preciso que as críticas ao Judiciário também considerem o desafio que é decidir em um sistema de normas que não é coerente. A legislação precisa ser coerente para alcançar a integridade do Direito. É verdade, contudo, que esse é um ponto que também tem melhorado em nosso ordenamento - com algumas exceções - após a Constituição Federal de 1988.

Em um cenário onde não há harmonia entre os Poderes - checks and balances - não há como existir a pretendida coerência.

Em que pesem as ressalvas acima descritas, o nosso sistema jurídico, sem falar do jurisdicionados, tendem a sentir uma grande melhoria caso a implantação das mudanças trazidas pelo novo Código de Processo Civil sejam de fato observadas.

As decisões proferidas em um sistema jurídico em que os tribunais devem uniformizar sua jurisprudência e mantê-la estável, íntegra e coerente -- Art. 926 do novo Código de Processo 
Civil - certamente são decisões mais aptas ao controle, à crítica, e consequentemente, há uma melhoria qualitativa do sistema jurídico.

A resposta correta fica para o juiz Hércules, o rompimento de paradigmas promovido pelo novo Código de Processo Civil e a uniformização da jurisprudência em um sistema que ao menos pretende buscar a integridade e a coerência, já será um considerável legado dessa nova legislação.

\section{REFERÊNCIAS}

ACKERMAN, Bruce. The Holmes Lectures: The Living Constitution. 2007. Faculty Scholarship Series. Paper 116. Yale Law School Faculty Scholarship Repository. Disponível em $<$ http://digitalcommons.law.yale.edu/fss_papers/116>. Compulsado em 07/01/2016.

BRASIL. Congresso Nacional. Senado Federal. Comissão de Juristas Responsável pela Elaboração de Anteprojeto de Código de Processo Civil. Código de Processo Civil: anteprojeto / Comissão de Juristas Responsável pela Elaboração de Anteprojeto de Código de Processo Civil. - Brasília: Senado Federal, Presidência, 2010

BRASIL. Lei $\mathrm{n}^{\mathrm{o}} 13.105$ de 16 de março de 2015. Disponível em http://www.planalto.gov.br/ccivil_03/_Ato2015-2018/2015/Lei/L13105.htm.

BRASIL. AgRG no REsp 382736/SC de 25/02/2004. Disponível em < https://ww2.stj.jus.br/processo/pesquisa/?tipoPesquisa=tipoPesquisaNumeroRegistro\&termo= 200101557448\&totalRegistrosPorPagina $=40 \&$ aplicacao=processos.ea $>. \quad$ Compulsado $\mathrm{em}$ $07 / 01 / 2016$.

BENJAMIN, Stuart Minor. Stepping into the Same River Twice: Rapidly Changing Facts and the Appellate Process. Texas Law Review. Vol. 78, n. 2, December, 1999. Disponível em $<$

http://scholarship.law.duke.edu/cgi/viewcontent.cgi?article=1009\&context=faculty_scholarshi p>. Compulsado em 18/03/2016.

COLLIER, Charles W. Precedent and Legal Authority: A Critical History, 1988. Wis. L. Ver. $771 \quad$ (1988). Disponível em http://scholarship.law.ufl.edu/cgi/viewcontent.cgi?article=1718\&context=facultypub. Compulsado em 10/01/2016.

DIDIER JUNIOR, Fredie. Transformações do Recurso Extraordinário. In: FUX, Luiz; NERY JUNIOR, Nelson; ARRUDA ALVIM WAMBIER, Teresa (coords.). Processo e 
Constituição: estuados em homenagem ao professor José Carlos Barbosa Moreira. São Paulo: RT, 2006.

DWORKIN, Ronald. Uma questão de princípio. 2. ed. São Paulo: Martins Fontes, 2005. Levando os direitos a sério. Trad. Nelson Boeira. São Paulo: Martins Fontes, 2002.

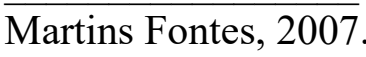
O Império do Direito. Trad. Jefferson Luiz Camargo. São Paulo:

A virtude soberana: a teoria e a prática da igualdade. Tradução Jussara Simões. 2 ed. São Paulo: Editora WMF Martins Fontes, 2011.

EISENBERG, Melvin Aron. The Nature of the Common Law. Cambrige: Havard University Press, 1991.

FUCK, Luciano Felício. Ampliação da idade de aposentadoria fortalece Poder Judiciário. Coluna do Observatório da Jurisdição Constitucional no Conjur. Disponível em < http://idp.edu.br/imprensa/2741-2015-05-11-20-55-26>. Compulsado em 08/01/2016.

FUX, Luiz. Novo CPC vai dotar Judiciário para enfrentar processos. 5 fev. 2010. Consultor Jurídico. Disponível em: $<$ http://www.conjur.com.br/2010-fev-05/cpc-dotar-judiciarioenfrentar-milhares-processos $>$. Compulsado em 15/01/2016.

HESSE, Konrad. Elementos de direito constitucional da República Federal da Alemanha. Porto Alegre: Sérgio Fabris Editor, 2008.

LUHMANN, Nicklas. Sociologia do Direito I. Rio de Janeiro: Tempo Brasileiro, 1983.

MACCORMICK, Neil. Retórica e o estado de direito. Trad. Conrado Hübner Mendes. Rio de Janeiro: Elsevier, 2008.

MARINONI, Luiz Guilherme. Precedentes obrigatórios. 2a ed. São Paulo: Revista dos Tribunais, 2011.

MENDES, Gilmar Ferreira. BRANCO, Paulo Gonet. Curso de direito constitucional. 9 ed. São Paulo: Saraiva, 2014. 
MESSITTE, Peter J. A Teoria dos precedentes no direito norte-americano. Palestra proferida no $8^{\circ}$ Ciclo Internacional de Conferências, promovido pela ANAMATRA XXIII, Cuiabá/MT, 14 a 18 de agosto de 2001. REv. TST, Brasília, vol. 67, nº 4, out/dez 2001. Disponível em < https://aplicacao.tst.jus.br/dspace/bitstream/handle/1939/51679/008_messitte.pdf?sequence=1 >. Compulsado em 15/03/2016.

ROSENN, Keith S. O jeito na cultura jurídica brasileira. São Paulo: Editora Renovar, 1998.

STRECK, Lenio Luiz. Verdade e Consenso. 5 ed. São Paulo: Saraiva, 2014.

Hermenêutica jurídica e(m) crise: uma exploração hermenêutica da construção do Direito. Porto Alegre: Livraria do Advogado, 1999.

Por que agora dá para apostar no projeto do novo CPC! 21 de outubro de 2013. Disponível em < http://www.conjur.com.br/2013-out-21/lenio-streck-agoraapostar-projeto-cpc>. Compulsado em 08/01/2016.

Dilema de dois juízes diante do fim do Livre convencimento no NCPC. 19 de março de 2015. Disponível em < http://www.conjur.com.br/2015-mar-19/sensoincomum-dilema-dois-juizes-diante-fim-livre-convencimento-ncpc $>$. Compulsado em $08 / 01 / 21016$.

Novo CPC terá mecanismos para combater decisionismos e arbitrariedades?. In Consultor Jurídico, 18 de dezembro de 2014. Disponível em < http://www.conjur.com.br/2014-dez-18/senso-incomum-cpc-mecanismos-combaterdecisionismos-arbitrariedades $>$. Compulsado em 08/01/2016.

O novo Código de Processo Civil (CPC) e as inovações hermenêuticas: $O$ fim do livre convencimento e a adoção do integracionismo dworkiano. In Revista de Informação Legislativa. Ano 52. Número 206. abr/jun 2015. Disponível em $<$ http://www2.senado.leg.br/bdsf/bitstream/handle/id/512448/001041585.pdf?sequence=1 $>$. Compulsado em 08/01/2016.

. Súmulas vinculantes em terrae brasilis: necessitamos de uma "teoria para a elaboração de precedentes"? In Revista Brasileira de Ciências Criminais. Vol. 78. Mai. 2009.

WAMBIER, Tereza Arruda Alvim. Estabilidade e adaptabilidade como objetivos do direito: civil law e common law. In Revista de Processo.n. 172. Jun. 2009. 
WOLKART, Erix Navarro. Precedente judicial no processo civil brasileiro: mecanismos de objetivação do processo. Salvador: Jus Podivm, 2013.

\title{
THE NEW CODE OF CIVIL PROCEDURE AND LAW AS INTEGRITY
}

\begin{abstract}
This article discusses the changes introduced in the new Code of Civil Procedure for the courts to standardize its jurisprudence and keep it stable, fair and consistent according to Ronald Dworkin 's theory of law as integrity and the chain novel or chain history in production of decisions at judgments. The article also deals with the lack of uniformity in court decisions in Brazil, there is no predictability, which creates legal uncertainty. The article deals with the Dworkin's theory, the law as integrity and its dual dimension. The integrity of the legislation and excess provisional measures has become another obstacle to overcome to achieve integrity in the system. Decisions given in a legal system where the courts must standardize its case and keep it stable, fair and consistent, as required by art. 926 of the New Civil Procedure Code are better able to control decisions to criticism. If the device is observed by the judges will be a qualitative improvement of the legal system.
\end{abstract}

Keywords: New code of civil procedure. Coherence. Law as integrity. 